\title{
Mutations in TGFbeta-RII and BAX mediate tumor progression in the later stages of colorectal cancer with microsatellite instability
}

\author{
Masakazu Yashiro*1,2, Kosei Hirakawa ${ }^{1}$ and C Richard Boland ${ }^{3}$
}

\begin{abstract}
Background: Microsatellite instability (MSI) occurs in 15\% of colorectal cancers (CRC). The genetic targets for mutation in the MSI phenotype include somatic mutations in the transforming growth factor beta receptor typell (TGFbetaRII), BAX, hMSH3 and hMSH6. It is not clear how mutations of these genes mediate tumor progression in the MSI pathway, and the temporal sequence of these mutations remains uncertain. In this study, early stage CRCs were examined for frameshift mutations in these target genes, and compared with late stage tumors and CRC cell lines.

Methods: We investigated 6 CRC cell lines and 71 sporadic CRCs, including 61 early stage cancers and 10 late stage cancers. Mutations of repetitive mononucleotide tracts in the coding regions of TGFbetaRII, BAX, hMSH3, hMSH6, IGFIIR and Fas antigen were identified by direct sequencing.

Results: Thirteen (18.3\%) of 71 CRC, including 9/61 (14.7\%) early stage cancers and 4/10 (40\%) late stage cancers, were identified as MSI and analyzed for frameshift mutations. No mutation in the target genes was observed in any of the 9 early stage MSI CRCs. In contrast, frameshift mutations of TGFbetaRII, BAX, hMSH3 and hMSH6 were present in 3/4 late stage MSI tumors. There is a statistical association $(p=0.014)$ between mutation in any one gene and tumor stage.

Conclusions: TGFbetaRIl, BAX, hMSH3 and hMSH6 mutations are relatively late events in the genesis of MSI CRCs. The frameshift mutations in these target genes might mediate progression from early to late stage cancer, rather than mediating the adenoma to carcinoma transition.
\end{abstract}

\section{Background}

Microsatellite instability (MSI) is present in $15 \%$ of colorectal carcinomas (CRCs)[1]. Inactivation of the DNA mismatch repair (MMR) system leads to widespread somatic mutations at microsatellite loci. MSI tumors have been found to display microsatellite alterations not only in introns but also in coding exons. Genetic targets of this type of genomic instability include the transforming growth factor $\beta$ receptor type II (TGFBRII), insulin-like growth factor II receptor (IGFIIR), BAX, Fas antigen, $h M S H 3$ and $h M S H 6$, all of which contain mononucleotide repeats in coding sequences [2,3]. Although it has been reported that MSI in introns is an early event in sporadic colorectal carcinogenesis [4,5], it is not known how mutations of these target genes are involved in tumor progression along the MSI pathway [2]. This study examined whether the frequency frameshift mutations in mononucleotide repeat regions within exons increases with stage in microsatellite unstable colorectal cancer. "Early stage cancer" was defined as intramucosal carcinoma, either carcinoma in situ or invasive cancer confined within the submucosa. For this study, "late stage cancer" was defined as any cancer invading the muscularis propria or serosa. Molecular events in early CRCs have not been well elucidated because of the limited availability of these cancers for detailed studies [5]. In this study, early stage MSI CRCs were examined for somatic frameshift mutations in the TGFBRII, IGFIIR and BAX, $h M S H 3$ and $h M S H 6$ genes, and compared with CRCS at more advanced stages and CRC cell lines.

* Correspondence: m9312510@med.osaka-cu.ac.jp

1 Department of Surgical Oncology, Osaka City University Graduate School of Medicine, Osaka, Japan

Full list of author information is available at the end of the article

() 2010 Yashiro et al; licensee BioMed Central Ltd. This is an Open Access article distributed under the terms of the Creative Commons BHITed Central Attribution License (http://creativecommons.org/licenses/by/2.0), which permits unrestricted use, distribution, and reproduction in any medium, provided the original work is properly cited. 


\section{Methods \\ Cell lines}

Six CRC cell lines: HCT116, LoVo, SW480, LS174t, DLD1 and HT29, were obtained from the American Type Culture Collection (Rockville, MD), and maintained in tissue culture containing $10 \%$ fetal calf serum (GIBCO) at $37^{\circ} \mathrm{C}$. LoVo, DLD1, SW480 and LS174t were derived from late stage colorectal cancer: LoVo [6] and DLD1 [7] were derived from Dukes' C tumor, and SW480 [8] and LS174t [9] were from Dukes' B tumor. Tumor stage of HCT116 [10] and HT29 [11] were not informative.

\section{Tumor tissues}

Seventy-one CRCs, including 61 early stage cancers and 10 late stage cancers, were collected for analysis. The histopathological diagnosis was determined according to the classification by the World Health Organization (WHO) [12] or by the General Rules of the Japanese Research Society for Cancer of Colon and Rectum [13]. Lymph node status was not taken into account. The tumor tissues were microdissected from formalin-fixed, paraffinembedded tissues sections as previously described [14]. Normal tissues were obtained from histologically normal mucosa or normal lymph nodes of the same patients. This study was approved by the Osaka City University ethics committee. Informed consent was obtained from all patients.

\section{DNA extraction}

Genomic DNA from the cell lines was extracted with phenol-chloroform. Genomic DNA from tumor tissues was isolated using Proteinase K (Sigma, St. Louis, MO) at a final concentration of $100 \mu \mathrm{g} / \mathrm{ml}$ and were incubated for $5 \mathrm{~h}$ at $55^{\circ} \mathrm{C}[14]$.

\section{Identification of MSI}

DNA was amplified by polymerase chain reaction (PCR) using ${ }^{32} \mathrm{P}$-end-labeled primers at microsatellite loci linked to the $h M S H 2$ locus on 2p16 (CA-5 and D2S123), the $h M L H 1$ locus on 3p23-21.3 (D3S1611 and D3S1561), the APC/MCC locus on 5q21 (D5S107 and D5S346), the p53 locus on 17p13 (D17S513 and p53 intron 1), and the DCC/SMAD4 locus on 18q21.3 (D18S35A and 18qDCC$T A$ ) [14]. We utilized stringent criteria for the determination of MSI from a National Cancer Institute workshop [15]. MSI-high (referred to as MSI) was defined by a novel band shift or allele at $>20 \%$ of the microsatellite loci tested when compared to non-neoplastic tissue from the same patient. Our assay for MSI was based on PCR amplification of a panel of 10 microsatellite primer pairs linked to tumor suppressor genes. In addition, poly $(\mathrm{T})_{27}$ mononucleotide repeats in the noncoding region of $\beta$ catenin exon 16 was performed using the following primer sets: 5'-GGTACTGACTTTGCTTGCTT-3' and
5'-ACTTAACACTACGAGAGACT-3'. In each case, one of the primer pairs was end-labeled with $\left[\gamma^{-}{ }^{32} \mathrm{P}\right] \mathrm{ATP}$ and subjected to PCR. The resulting PCR products were analyzed for MSI by electrophoresis in $8 \%$ polyacrylamide gel containing $7.5 \mathrm{M}$ urea and $0.5 \times \mathrm{TBE}$.

\section{Frameshift mutation analysis}

Mutations of repetitive mononucleotide tracts in the coding regions of TGFBRII, IGFIIR, BAX, hMSH3, hMSH6 and Fas antigen were identified using the following primer sets; 5'-CTTTATTCTGGAAGATGCTGC-3' and 5'-GAAGAAAGTCTCACCAGGC-3' for the poly(A) 10 tract of TGFBRII, 5'-GCAGGTCTCCTGACTCAGAA-3' and 5'-GAAGAAGATGGCTGTGGAGC-3' for the poly $(\mathrm{G})_{8}$ tract of IGFIIR, 5'-ATCCAGGATCGAGCAGGGCG-3' and 5'-ACTCGCTCAGCTTCTTGGTG-3' for the poly $(\mathrm{G})_{8}$ tract of $B A X, 5^{\prime}$-AGCTGGATGATGCTGTAAAT-3' and 5'-TTCCTCACCTGCAAAGTACT-3' for the poly(A) ${ }_{8}$ tract of $h M S H 3,5$ '-CGCCCAGTAATTCTGTTG-3' and 5'-CATTTTCCTGCTCCTCTTC-3' for the poly $(\mathrm{C})_{8}$ tract of $h M S H 6$, and 5'-ACCCGGACCCAGAATACCAA-3' and 5'-GCAAGGGTCACAGTGTTCAC-3' for the poly $(\mathrm{T})_{7}$ tract of Fas antigen. To confirm mutations observed as band shifts, DNA was excised from the gel, purified with the Microspin columns (Pharmacia Biotec, Inc., Uppsala, Sweden), and reamplified with the same primer. The amplified products were sequenced by the dideoxychain termination method, with the AmpliCycle sequencing kit (Perkin-Elmer, Branchburg, NJ).

\section{Results}

\section{Frameshift mutations in CRC cell lines}

It has been reported that HCT116, LoVo, LS174t and DLD1 have the MSI phenotype, whereas SW480 and HT29 do not [16]. In this study, frameshift mutations in the (A) ${ }_{10}$ tract of TGF $\beta R I I$ were found in all 4 MMR-deficient cell lines: HCT116, LoVo, LS174t and DLD1. All cell lines have only mutant alleles of TGF $\beta$ RII, either $(A)_{9}$ or $(A)_{8}$. Microsatellite alterations in the $(G)_{8}$ tract of $B A X$ were present in HCT116, LoVo and LS174t. LoVo and LS174t cells had only $(G)_{9}$ and $(G)_{7}$ mutant BAX alleles; HCT116 had one $(G)_{7}$ mutant allele and one $(G)_{8}$ wildtype allele. Deletions in the $(\mathrm{A})_{8}$ tract of the coding sequence of $h M S H 3$ were present in HCT116. Insertion and deletion mutations in the $(\mathrm{C})_{8}$ tract of $h M S H 6$ were detected in HCT116 and LS174t, respectively. In contrast, the MMR-proficient cell lines SW480 and HT29 demonstrated microsatellite stability, and did not have mutations in TGFBRII, BAX, hMSH3 or hMSH6. No alterations in the $(\mathrm{G})_{8}$ tract of IGFIIR or the $(\mathrm{T})_{7}$ tract of 


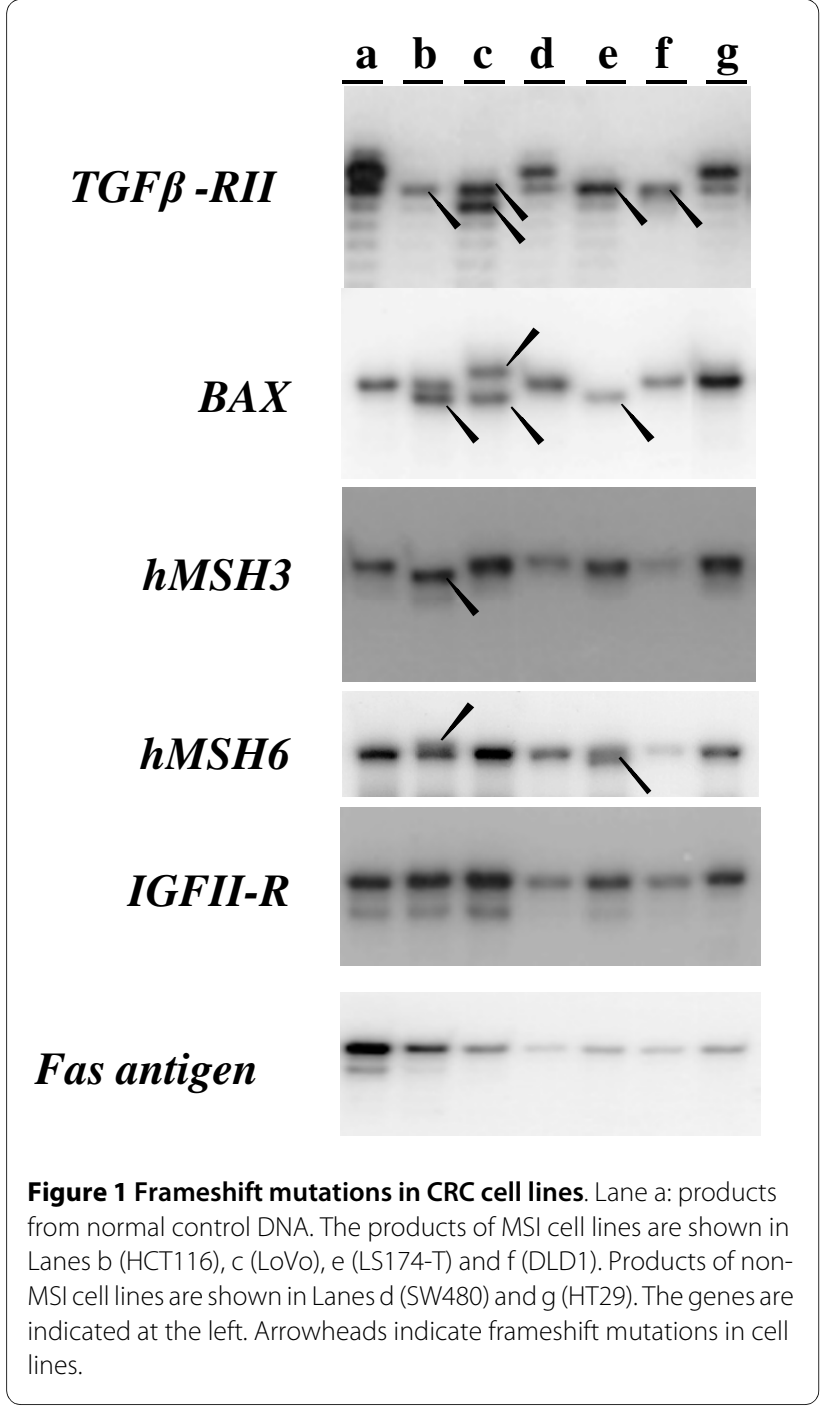

Fas antigen were found in any of the cell lines examined (Figure 1).

\section{Frequencies of frameshift mutations in early and late stage sporadic MSI CRCs}

Thirteen of 71(18.3\%) sporadic CRCs, including 9/61 (14.7\%) early stage CRCs and 4/10 (40\%) late stage cancers were identified as MSI tumors (Table 1), and these tumors were analyzed for frameshift mutations. Mutations in the noncoding region of $\beta$-catenin, which contains a $(\mathrm{T})_{27}$ sequence, were present in 7/9 MSI early stage CRCs (patients 1-9) and 3/4 MSI-H late stage CRCs (patients 10-13) (Figure 2A). No frameshift mutations in the target genes were present in any MSI early stage CRCs. In contrast, frameshift mutations of TGF $\beta R I I$, $B A X, h M S H 3$ and $h M S H 6$ were present in $3 / 4$ late stage CRCs (Table 1). A significant difference $(\mathrm{p}=0.014)$ was found in the frequency of frameshift mutations between early stage and. late stage (Table 2). TGFBRII and BAX mutations were found in the late stage tumors of patients 11 and 10, respectively (Figure 2B). $h M S H 3$ mutations were present in patients 11 and 12, and an hMSH6 mutation was found in patient 12. Each mutation was found to be a $1 \mathrm{bp}$ deletion in the polynucleotide tract (Figure 3). No frameshift mutations in IGFIIR or Fas antigen were found in any CRC.

\section{Discussion}

Although CRCs with the MSI phenotype evolve because of loss of DNA MMR activity, there is little consensus on the sequence and timing of target gene inactivation in the evolution of tumors that occur through this pathway. It has been reported that the appearance of MSI, at least at noncoding microsatellites, is an early event in Lynch syndrome CRCs [4,17], and that frameshift alterations in the functionally critical target genes may occur at an early stage in these tumors [18-20]. TGF $\beta R I I$ frameshift mutations are present in $80-90 \%$ of MSI CRCs, and it has been reported that these occur at the adenoma-carcinoma transition in MSI adenomas [21,22]. The precise timing of the onset of MSI, and the occurrence of mutations at other genetic targets, have not been confidently determined.

In this study, we examined the timing of frameshift mutations of TGFBRII, IGFIIR, BAX, hMSH3, hMSH6 and Fas antigen in 9 early stage and 4 late stage MSI CRCs. Interestingly, no mutations were identified in any early stage MSI-H CRC at TGF $\beta R I I, B A X, h M S H 3$ or $h M S H 6$, but these were relatively frequent events in late stage MSI CRCs, and in the MSI CRC cell lines. There is a statistical association between mutation in any one gene and tumor stage. The frequency of frameshift mutations in mononucleotide repeat regions within exons might increase with stage in microsatellite unstable colorectal cancer. Our findings suggest that TGF $\beta R I I, B A X, h M S H 3$ and $h M S H 6$ frameshift mutations are relatively later stage events in tumor progression for sporadic CRC with MSI. It has been reported that TGF $\beta R I I$ mutations are infrequent in the early stages of sporadic gastric cancers with MSI [23], but these occur more frequently in gastric tumors that are larger [24]. It has been reported that the loss of TGF $\beta R I I$ in intestinal epithelial cells promotes the invasion and malignant transformation of tumors initiated by $A P C$ mutations [25]. However, few studies have clarified how mutations of the target genes we have studied mediate tumor development in the MSI pathway. These findings suggested that the mutations of TGF $\beta R I I$, $B A X, h M S H 3$, and $h M S H 6$ might play an important role in cancer progression from early to late stage tumors, rather than early in carcinogenesis. However, there still may be additional, currently unappreciated genes or DNA sequences involved in the process [18,26-28]. Interestingly, no microsatellite mutations in IGFIIR and Fas 
Table 1: Frameshift mutations in MSI CRCs

\begin{tabular}{|c|c|c|c|c|c|c|c|c|c|c|c|}
\hline \multirow[t]{2}{*}{ Patient number } & \multirow[t]{2}{*}{ Stage } & \multirow[t]{2}{*}{ Depth of invasion ${ }^{a}$} & \multirow{2}{*}{$\begin{array}{c}\text { Tumor size } \\
\text { (mm) }\end{array}$} & \multirow[t]{2}{*}{ Location $^{b}$} & \multirow[t]{2}{*}{ MSI } & \multicolumn{6}{|c|}{ Mutations in mononucleotide repeat tracts } \\
\hline & & & & & & TGFßRII & $B A X$ & hMSH3 & hMSH6 & IGFIIR & Fas antigen \\
\hline 1 & Early & $\mathrm{m}$ & 4 & A & $2 / 6$ & $-c$ & - & $\mathrm{NI}^{d}$ & - & - & - \\
\hline 2 & Early & $\mathrm{m}$ & 4 & A & $2 / 8$ & - & - & $\mathrm{NI}$ & - & - & - \\
\hline 3 & Early & $\mathrm{m}$ & 3 & $\mathrm{~s}$ & $3 / 8$ & - & - & - & - & - & - \\
\hline 4 & Early & sm & 8 & $\mathrm{R}$ & $3 / 8$ & - & - & - & - & - & - \\
\hline 5 & Early & sm & 14 & A & $2 / 5$ & - & - & $\mathrm{NI}$ & - & - & - \\
\hline 6 & Early & $\mathrm{sm}$ & 8 & $\mathrm{~T}$ & $3 / 8$ & - & - & - & - & - & - \\
\hline 7 & Early & $\mathrm{sm}$ & 4 & D & $3 / 10$ & - & - & - & - & - & - \\
\hline 8 & Early & sm & 12 & $\mathrm{NI}$ & $2 / 8$ & - & - & $\mathrm{NI}$ & - & - & - \\
\hline 9 & Early & $\mathrm{sm}$ & 13 & $\mathrm{R}$ & $2 / 9$ & - & - & - & - & - & - \\
\hline 10 & Late & $\mathrm{mp}$ & 9 & $\mathrm{R}$ & $2 / 8$ & - & De & - & - & - & - \\
\hline 11 & Late & $\mathrm{mp}$ & 20 & $S$ & $3 / 9$ & $\mathrm{De}^{e}$ & - & De & - & - & - \\
\hline 12 & Late & $\mathrm{mp}$ & 65 & A & $4 / 10$ & - & - & $\mathrm{De}$ & De & - & - \\
\hline 13 & Late & $\mathrm{mp}$ & 24 & $S$ & $2 / 9$ & - & - & - & - & - & - \\
\hline
\end{tabular}

am, carcinoma tissues were restricted to the mucosa; sm, the deepest carcinoma invasion was in the submucosa; mp, the deepest carcinoma penetration reached the muscularis propria.

${ }^{b} \mathrm{~A}$, ascending colon; $\mathrm{T}$, transverse colon; $\mathrm{D}$ descending colon; $\mathrm{S}$, sigmoid colon; $\mathrm{R}$, rectum.

$c_{-}$, wild type.

d $\mathrm{NI}$, not informative.

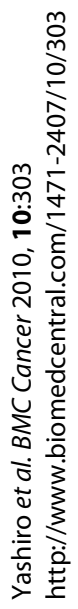

e De, deletion. 


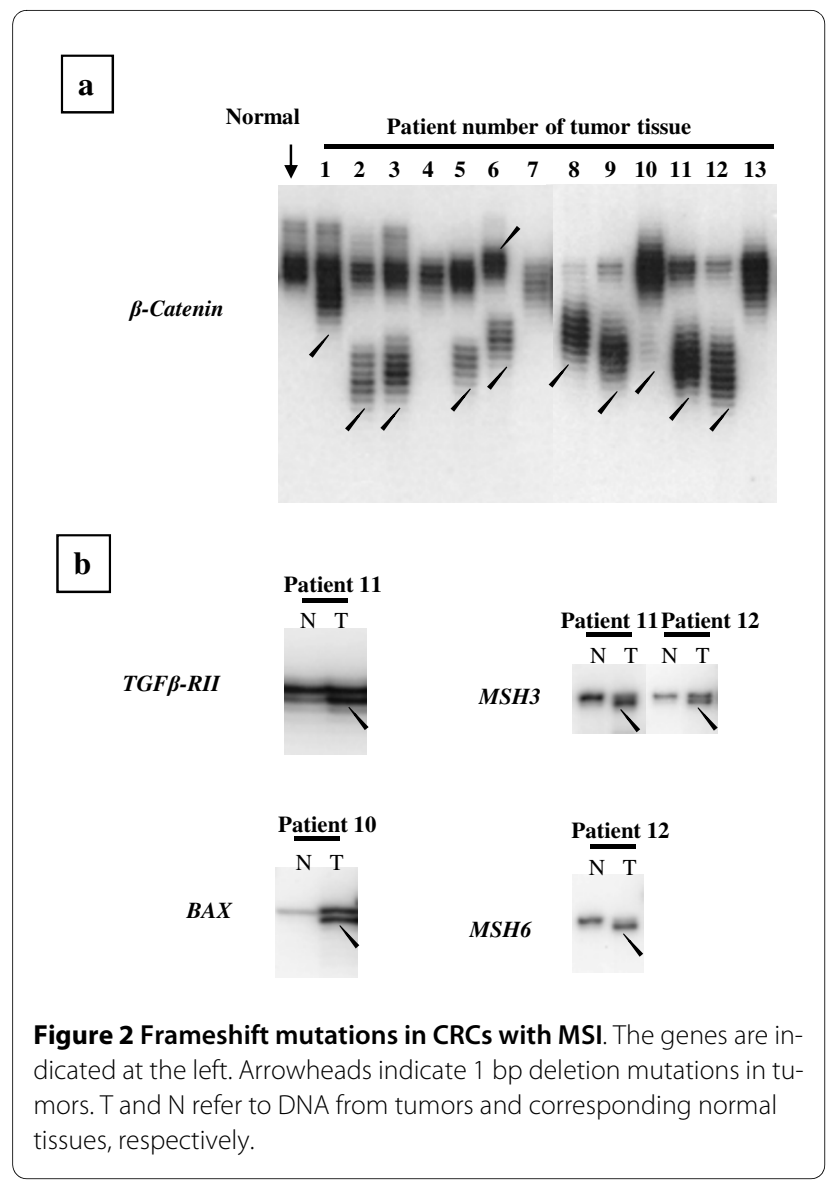

antigen were found in any cell line or in any CRC. It has also been reported that no mutations in the IGFIIR genes were found in $27 \mathrm{MSI}-\mathrm{H}$ gastric tumors [29]. These findings suggest that mononucleotide repeat of IGFIIR and Fas antigen might be unimportant as target genes in MMR-deficient CRCs. A limitation of our study is the small number of tumor samples, while a significant difference between the early stage cancer and late stage cancers was recognized. Large numbers of patients with MSI cancer might be necessary in the future to conclude the correlation between tumor stage and frameshift mutations in target gene.

Table 2: Correlation between tumor stage and frameshift mutations.

\begin{tabular}{llll}
\hline & \multicolumn{2}{c}{ Frameshift mutation } & \\
\cline { 2 - 3 } Tumor stage & positive & negative & p value \\
& & & \\
\hline Early & 0 & 9 & 0.014 \\
Late & 3 & 1 & \\
\hline $\begin{array}{l}\text { Significance level of difference was determined using Fisher's } \\
\text { exact test. }\end{array}$ &
\end{tabular}

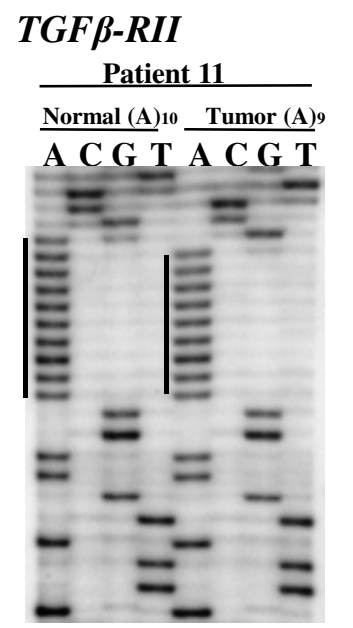

\section{hMSH3}

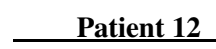

Normal (A)8 Tumor (A)

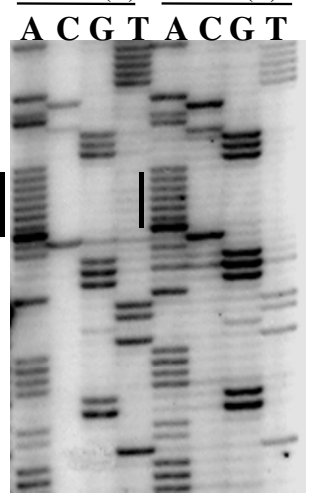

\section{$B A X$}

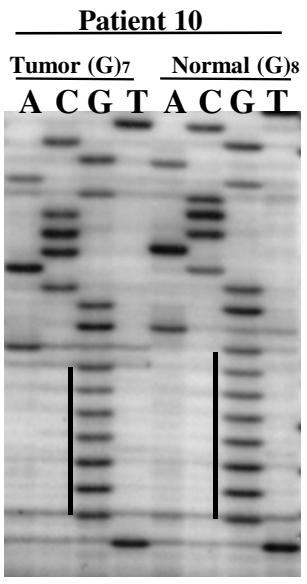

\section{hMSH6}

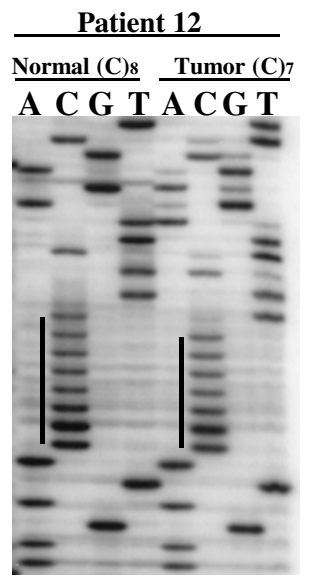

Figure 3 Sequence analysis of frameshift mutations in late stage CRCs. Single one bp deletions in the mononucleotide repeats were found in each case.

\section{Conclusions}

Our data confirm that MSI can be found very early in the evolution of a colorectal tumor with MSI, we propose that not all sequence alterations are equivalent, and that mutations in the coding microsatellites of TGF $\beta R I I$ and $B A X$ mediate progression from early to late stage CRC with MSI. These finding raise interesting possibilities for diagnosis as well as treatment.

\section{Competing interests}

The authors declare that they have no competing interests.

\section{Authors' contributions}

MY participated in the study design, and carried out PCR experiments, sequencing analysis, interpretation of data, and paper preparation. $\mathrm{KH}$ carried out data analysis and interpretation. CRB carried out data analysis, interpretation, and paper preparation. All authors have read and approved of the final manuscript. 


\section{Acknowledgements}

We thank Christina Chang, PhD for technical assistance and critical review of the manuscript.

\section{Author Details}

'Department of Surgical Oncology, Osaka City University Graduate School of Medicine, Osaka, Japan, 2Oncology Institute of Geriatrics and Medical Science, Osaka City University Graduate School of Medicine, Osaka, Japan and ${ }^{3}$ Division of Gastroenterology, Baylor University Medical Center, Dallas, Texas, USA

Received: 12 February 2010 Accepted: 18 June 2010

Published: 18 June 2010

\section{References}

1. Boland CR: The molecular biology of gastrointestinal cancer: implications for diagnosis and therapy. Gastrointestinal endoscopy clinics of North America 2008, 18(3):401-413. vii

2. Arnold CN, Goel A, Blum HE, Boland CR: Molecular pathogenesis of colorectal cancer: implications for molecular diagnosis. Cancer 2005, 104(10):2035-2047.

3. Yamamoto H, Gil J, Schwartz S Jr, Perucho M: Frameshift mutations in Fas, Apaf-1, and Bcl-10 in gastro-intestinal cancer of the microsatellite mutator phenotype. Cell death and differentiation 2000, 7(2):238-239.

4. Pedroni M, Sala E, Scarselli A, Borghi F, Menigatti M, Benatti P, Percesepe A, Rossi G, Foroni M, Losi L, et al:: Microsatellite instability and mismatchrepair protein expression in hereditary and sporadic colorectal carcinogenesis. Cancer research 2001, 61(3):896-899.

5. Kambara T, Matsubara N, Nakagawa H, Notohara K, Nagasaka T, Yoshino T, Isozaki H, Sharp GB, Shimizu K, Jass J, et al:. High frequency of low-level microsatellite instability in early colorectal cancer. Cancer research 2001, 61(21):7743-7746.

6. Drewinko B, Romsdahl MM, Yang LY, Ahearn MJ, Trujillo JM: Establishment of a human carcinoembryonic antigen-producing colon adenocarcinoma cell line. Cancer research 1976, 36(2 Pt 1):467-475.

7. Dexter DL, Barbosa JA, Calabresi P: N,N-dimethylformamide-induced alteration of cell culture characteristics and loss of tumorigenicity in cultured human colon carcinoma cells. Cancer research 1979, 39(3):1020-1025.

8. Leibovitz A, Stinson JC, McCombs WB, McCoy CE, Mazur KC, Mabry ND: Classification of human colorectal adenocarcinoma cell lines. Cancer research 1976, 36(12):4562-4569.

9. Tom BH, Rutzky LP, Jakstys MM, Oyasu R, Kaye Cl, Kahan BD: Human colonic adenocarcinoma cells. I. Establishment and description of a new line. In vitro 1976, 12(3):180-191.

10. Brattain MG, Fine WD, Khaled FM, Thompson J, Brattain DE: Heterogeneity of malignant cells from a human colonic carcinoma. Cancer research 1981, 41(5):1751-1756.

11. Chen TR, Drabkowski D, Hay RJ, Macy M, Peterson W Jr: WiDr is a derivative of another colon adenocarcinoma cell line, HT-29. Cancer genetics and cytogenetics 1987, 27(1):125-134

12. Jass JR, Sobin LH, Watanabe H: The World Health Organization's histologic classification of gastrointestinal tumors. A commentary on the second edition. Cancer 1990, 66(10):2162-2167.

13. General rules for clinical and pathological studies on cancer of the colon, rectum and anus. Part II. Histopathological classification. Japanese Research Society for Cancer of the Colon and Rectum. Jpn J Surg 1983, 13(6):574-598.

14. Yashiro M, Carethers JM, Laghi L, Saito K, Slezak P, Jaramillo E, Rubio C, Koizumi K, Hirakawa K, Boland CR: Genetic pathways in the evolution of morphologically distinct colorectal neoplasms. Cancer research 2001, 61(6):2676-2683.

15. Boland CR, Thibodeau SN, Hamilton SR, Sidransky D, Eshleman JR, Burt RW, Meltzer SJ, Rodriguez-Bigas MA, Fodde R, Ranzani GN, et al:: A National Cancer Institute Workshop on Microsatellite Instability for cancer detection and familial predisposition: development of international criteria for the determination of microsatellite instability in colorectal cancer. Cancer research 1998, 58(22):5248-5257.

16. Carethers JM, Pham TT: Mutations of transforming growth factor beta 1 type II receptor, BAX, and insulin-like growth factor II receptor genes in microsatellite unstable cell lines. In Vivo 2000, 14(1):13-20.

17. Lynch HT, Lynch PM, Lanspa SJ, Snyder CL, Lynch JF, Boland CR: Review of the Lynch syndrome: history, molecular genetics, screening, differential diagnosis, and medicolegal ramifications. Clinical genetics 2009, 76(1):1-18.

18. Imai K, Yamamoto H: Carcinogenesis and microsatellite instability: the interrelationship between genetics and epigenetics. Carcinogenesis 2008, 29(4):673-680.

19. Akiyama Y, Yagi OK, Ishikawa T, Nagasaki H, Saitoh K, Yuasa Y: Genetic alterations are frequent in APC but rare in the TGF-beta type II receptor gene in cancer in adenomas of the colon. Cancer Lett 1998, 125(12):89-96.

20. Konishi M, Kikuchi-Yanoshita R, Tanaka K, Muraoka M, Onda A, Okumura Y, Kishi N, Iwama T, Mori T, Koike M, et al: Molecular nature of colon tumors in hereditary nonpolyposis colon cancer, familial polyposis, and sporadic colon cancer. Gastroenterology 1996, 111(2):307-317.

21. Grady WM, Rajput A, Myeroff L, Liu DF, Kwon K, Willis J, Markowitz S: Mutation of the type II transforming growth factor-beta receptor is coincident with the transformation of human colon adenomas to malignant carcinomas. Cancer research 1998, 58(14):3101-3104.

22. Shin KH, Park YJ, Park JG: Mutational analysis of the transforming growth factor beta receptor type II gene in hereditary nonpolyposis colorectal cancer and early-onset colorectal cancer patients. Clin Cancer Res 2000, 6(2):536-540.

23. Ogata S, Tamura G, Endoh Y, Sakata K, Ohmura K, Motoyama T: Microsatellite alterations and target gene mutations in the early stages of multiple gastric cancer. J Pathol 2001, 194(3):334-340.

24. Pinto M, Oliveira C, Cirnes L, Carlos Machado J, Ramires M, Nogueira A, Carneiro F, Seruca R: Promoter methylation of TGFbeta receptor I and mutation of TGFbeta receptor II are frequent events in MSI sporadic gastric carcinomas. J Pathol 2003, 200(1):32-38.

25. Munoz NM, Upton M, Rojas A, Washington MK, Lin L, Chytil A, Sozmen EG, Madison BB, Pozzi A, Moon RT, et al:: Transforming growth factor beta receptor type II inactivation induces the malignant transformation of intestinal neoplasms initiated by Apc mutation. Cancer research 2006, 66(20):9837-9844

26. Alazzouzi H, Davalos V, Kokko A, Domingo E, Woerner SM, Wilson AJ Konrad L, Laiho P, Espin E, Armengol M, et al:: Mechanisms of inactivation of the receptor tyrosine kinase EPHB2 in colorectal tumors. Cancer research 2005, 65(22):10170-10173.

27. Woerner SM, Benner A, Sutter C, Schiller M, Yuan YP, Keller G, Bork P, Doeberitz MK, Gebert JF: Pathogenesis of DNA repair-deficient cancers: a statistical meta-analysis of putative Real Common Target genes. Oncogene 2003, 22(15):2226-2235

28. Korff S, Woerner SM, Yuan YP, Bork P, von Knebel Doeberitz M, Gebert J: Frameshift mutations in coding repeats of protein tyrosine phosphatase genes in colorectal tumors with microsatellite instability. BMC cancer 2008, 8:329.

29. Kim JJ, Baek MJ, Kim L, Kim NG, Lee YC, Song SY, Noh SH, Kim H: Accumulated frameshift mutations at coding nucleotide repeats during the progression of gastric carcinoma with microsatellite instability. Lab Invest 1999, 79(9):1113-1120.

Pre-publication history

The pre-publication history for this paper can be accessed here: http://www.biomedcentral.com/1471-2407/10/303/prepub

doi: 10.1186/1471-2407-10-303

Cite this article as: Yashiro et al., Mutations in TGFbeta-RII and BAX mediate tumor progression in the later stages of colorectal cancer with microsatellite instability BMC Cancer 2010, 10:303 